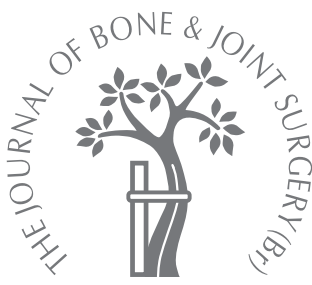

TRAUMA: RESEARCH

\title{
Biomechanical testing of a concept of posterior pelvic reconstruction in rotationally and vertically unstable fractures
}

O. Berber,

A. A. Amis,

A. C. Day

From St George's

Hospital, London,

United Kingdom
O. Berber, MBBS, MRCS BSc(Hons), Orthopaedic Registrar

A. C. Day, MBBChir, BMedBiol, FRCS(Orth),

Consultant Orthopaedic

Surgeon

St George's Hospital, Blackshaw Road, Tooting, London SW17 0OT, UK.

A. A. Amis, PhD, DSc(Eng), Professor of Orthopaedic Surgery

Department of Mechanical Engineering and

Musculoskeletal Surgery Imperial College London, London SW7 2AZ, UK.

Correspondence should be sent to $\mathrm{Mr} \mathrm{O}$. Berber; e-mail: onurberber@yahoo.co.uk

(C)2011 British Editorial Society of Bone and Joint Surgery doi:10.1302/0301-620X.93B2. $24567 \$ 2.00$

$J$ Bone Joint Surg $[\mathrm{Br}]$ 2011;93-B:237-44. Received 12 May 2010; Accepted after revision 5 October 2010

The purpose of this study was to assess the stability of a developmental pelvic reconstruction system which extends the concept of triangular osteosynthesis with fixation anterior to the lumbosacral pivot point. An unstable Tile type-C fracture, associated with a sacral transforaminal fracture, was created in synthetic pelves. The new concept was compared with three other constructs, including bilateral iliosacral screws, a tension band plate and a combined plate with screws. The pubic symphysis was plated in all cases. The pelvic ring was loaded to simulate single-stance posture in a cyclical manner until failure, defined as a displacement of $2 \mathrm{~mm}$ or $2^{\circ}$. The screws were the weakest construct, failing with a load of $50 \mathrm{~N}$ after 400 cycles, with maximal translation in the craniocaudal axis of $12 \mathrm{~mm}$. A tension band plate resisted greater load but failure occurred at $100 \mathrm{~N}$, with maximal rotational displacement around the mediolateral axis of $2.3^{\circ}$.

The combination of a plate and screws led to an improvement in stability at the $100 \mathrm{~N}$ load level, but rotational failure still occurred around the mediolateral axis. The pelvic reconstruction system was the most stable construct, with a maximal displacement of $2.1^{\circ}$ of rotation around the mediolateral axis at a load of $500 \mathrm{~N}$.

Vertical shear injuries to the pelvis are almost always due to high-energy trauma with disruption of the anterior and posterior parts of the pelvic ring. There is by definition both vertical and rotational pelvic instability. ${ }^{1}$ These fracture patterns represent a particularly complex problem for fixation when associated with transforaminal sacral fractures, described by Denis, Davis and Comfort ${ }^{2}$ as 'zone 2' fractures. The difficulty lies in achieving stable fixation without applying compressive forces across the fracture, which carries the possibility of injury to a sacral nerve root. The incidence of unstable sacral fractures after major pelvic trauma can be as high as $30 \% .^{2}$

Internal fixation is now considered to be definitive management for posterior injuries to the pelvic ring. ${ }^{3,4}$ The current methods of treatment include iliosacral screws, anterior or posterior sacroiliac plates, sacral bars, tension band plates and, more recently, triangular osteosynthesis. Greater stability is achieved with a combination of anterior and posterior fixation, ${ }^{5,6}$ which gives a better quality of reduction and lower rates of malunion. ${ }^{7}$ These fixation techniques have been tested under dynamic loading conditions with variable outcomes. Systematic analysis has shown that implant failure ranges from $2 \%$ to $17.3 \% .^{7}$
A developmental pelvic reconstruction system has been designed to address the recognised mechanisms of failure of posterior fixation. This construct embodies the concept of the lumbosacral pivot point ${ }^{8}$ as a key feature, and extends the idea of triangular osteosynthesis. ${ }^{9,10}$ The pivot point is defined as the intersection of the middle osteoligamentous column and the lumbosacral intervertebral disc. It is the axis of rotation between the vertebral body of L5 and the sacrum. Constructs gain biomechanical advantage when placed dorsal to the pivot point and extend anterior to it, thereby resisting the moment around this point and providing better rotational stability around the mediolateral axis. The concept of the pelvic reconstruction system comprises a trans-sacral bar which passes through the body of S1 akin to the track of an iliosacral screw and is thus located anterior to the pivot point. This bar is connected to a more conventional transiliac bar passing between the posterior iliac crests and posterior to the spinal canal by means of link bars that lie on the outer table of the wing of the ilium. This creates a parallelogram which should resist translation in anteroposterior and mediolateral directions and around the craniocaudal axis. Rotation around the mediolateral axis is then prevented by linking the posterior sacral bar to 
Table I. Methods of fixation of the pelvis and the respective load applied

\begin{tabular}{lc}
\hline Fixation method & Load (N) \\
\hline 1. IS & 50 \\
2. TBP & 100 \\
3. TBP & 200 \\
4. IS/TBP & 100 \\
5. IS/TBP & 300 \\
6. IS/TBP & 400 \\
7. IS/TBP & 500 \\
8. PRS & 400 \\
9. PRS & 500 \\
\hline
\end{tabular}

* IS, iliosacral screw; TBP, tension band plate; PRS, pelvic reconstruction

pedicle screws in S1 with $5.5 \mathrm{~mm}$ rods, similar to those used in spinal instrumentation, thereby extending the concept of triangular osteosynthesis. The spinal instrumentation may be extended to the L4 and L5 pedicles in the case of spinopelvic dissociation, as observed in $\mathrm{H}$ - and U-pattern fractures of the sacrum.

This study evaluated the biomechanical stability provided by the developmental pelvic reconstruction system concept using plastic Sawbone pelves (Sawbones Europe $\mathrm{AB}$, Malmö, Sweden) with simulated Tile type-C and sacral transforaminal fracture patterns under cyclical loading in the physiological range. It was hypothesised that the stability of the pelvic reconstruction system under cyclical loading would be superior to that provided by iliosacral screws, a tension band plate or a combination of the two.

\section{Materials and Methods}

Synthetic pelves were prepared to simulate single-leg stance. Each method of fixation was loaded sequentially to the point of failure. Nine combinations of construct and peak cyclical load were analysed (Table I). Synthetic pelves were selected to minimise the inter-specimen variability often associated with the testing of different fixation methods in cadaveric bone of variable mineral density. The model tested the relative stability of the methods of fixation by measuring the relative movements across the fracture in six degrees of freedom. The authors appreciate that a distinct and separate protocol will be required to assess the mechanisms of failure at the interface of the device with cancellous bone. A vertical shear fracture pattern was reproduced that consisted of bilateral fractures of the sacroiliac joint with an ipsilateral sacral transforaminal fracture (Denis type 2). Diastasis of the pubic symphysis was created and stabilised with a non-proprietary custom-made fourhole symphyseal locking plate. Although this fracture pattern is not commonly seen clinically, it was chosen to create a state of maximal instability so as to test the constructs more robustly.

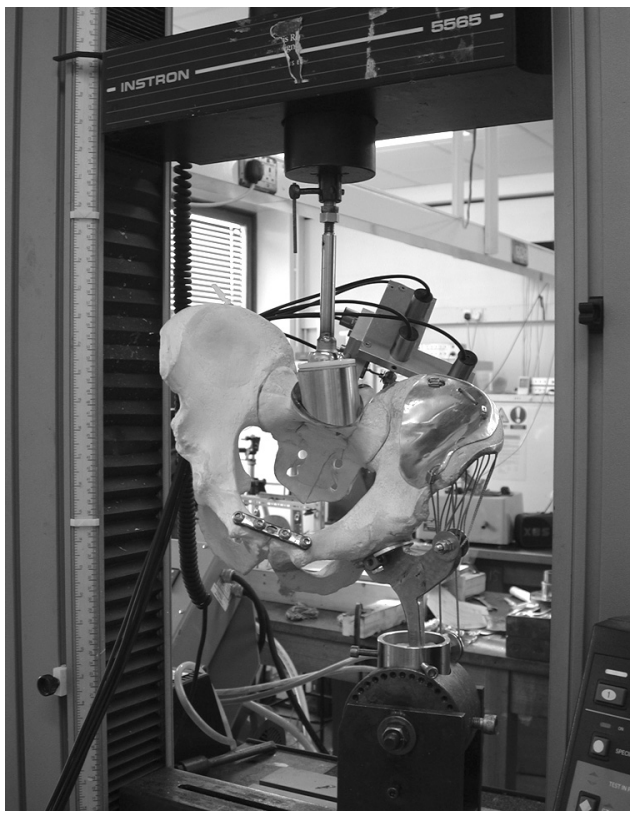

Fig. 1a

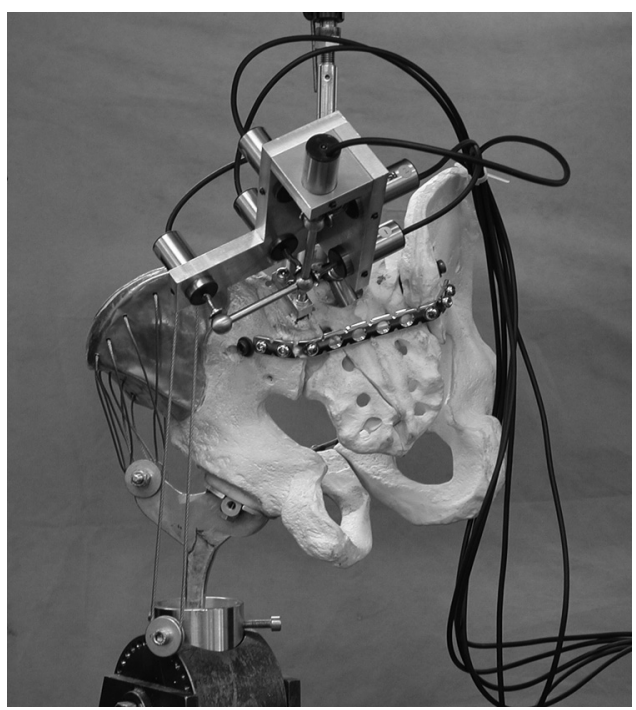

Fig. 1b

Photographs showing the experimental set-up with a pelvis in a single-leg stance model, a) the pelvis was fixed to a mobile base plate through a semi-constrained hip prosthesis and loaded through a ball joint on the body of S1 by an Instron material testing machine. Hip abductors were simulated by steel cables attached from the potting cylinder and hip prosthesis to the reinforced lateral iliac wall and in b) posterior view showing the attachment of the linear voltage displacement transducer array reference frames to the left iliac crest and the sacral loading plate, respectively.

After repair of the fracture, the pelves were articulated with a semi-constrained hip providing a fulcrum at the hip joint allowing three degrees of freedom. Gluteus medius and maximus were simulated with steel cables extending from a reinforced iliac wing to the greater trochanter of the hip and the potting cylinder, respectively (Fig. 1). The 


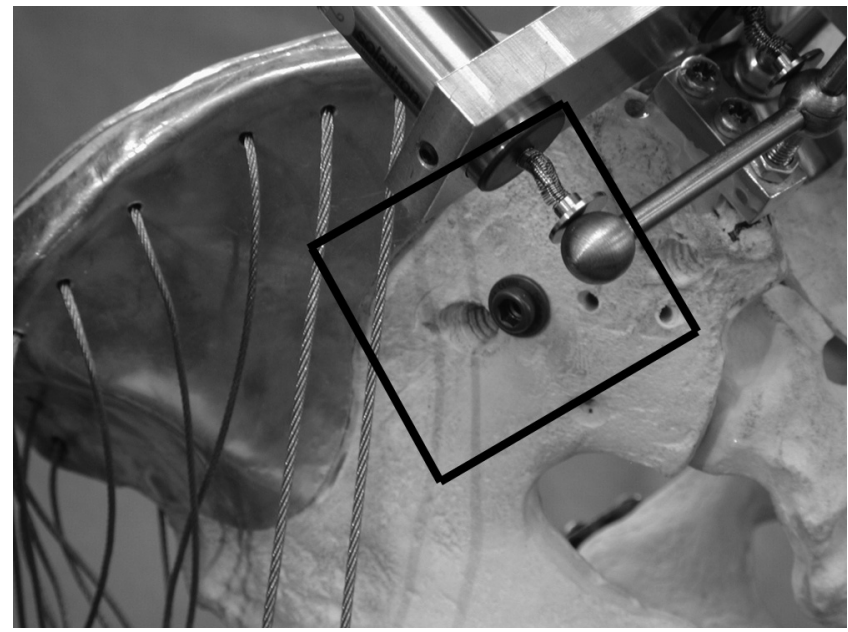

Fig. 2a

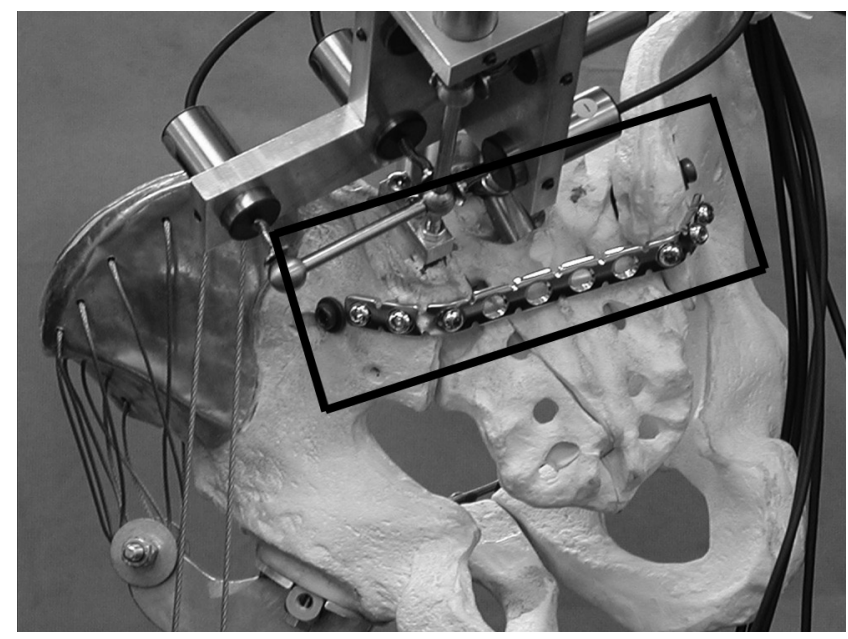

Fig. 2c

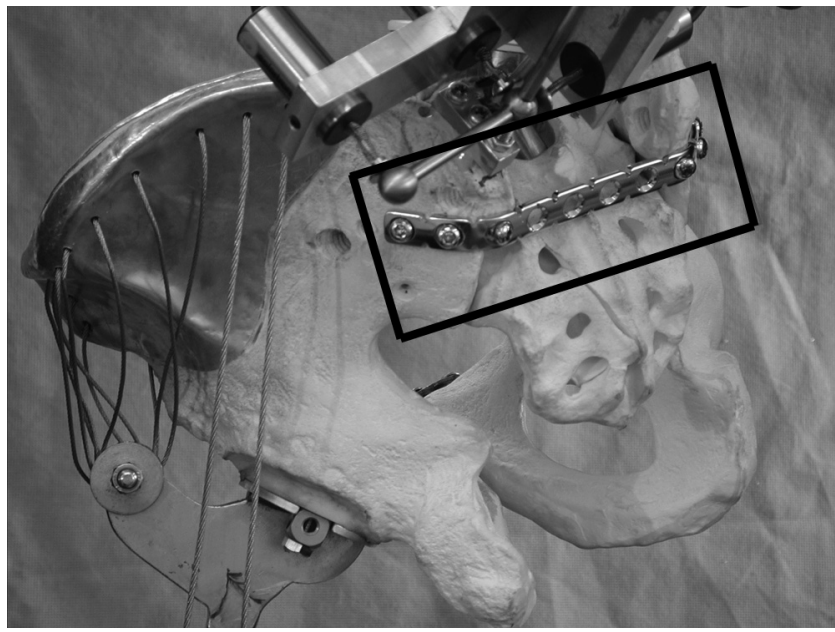

Fig. 2b

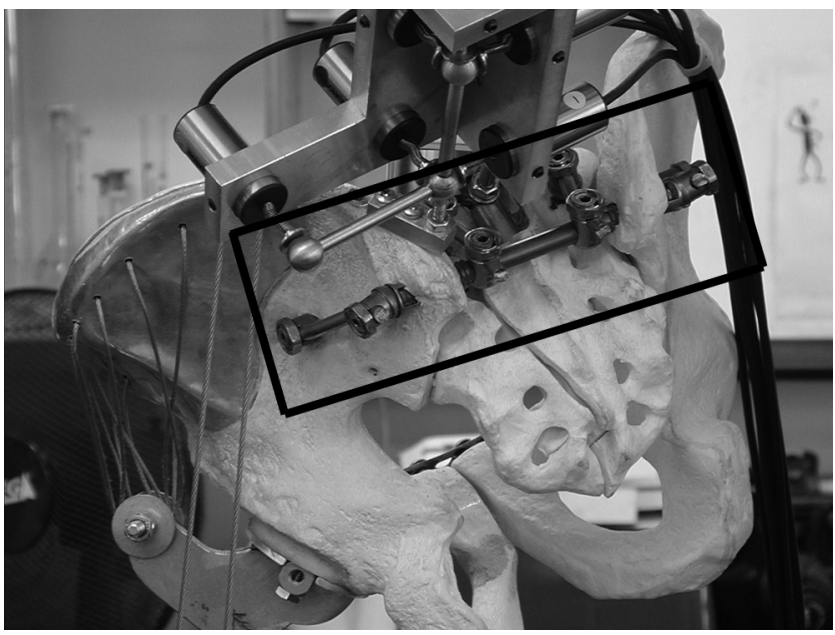

Fig. 2d

Photographs of the different methods of fixation (black rectangles) showing a) bilateral S1 iliosacral screw fixation, b) tension band plate, c) combined bilateral iliosacral screws and tension band plate, and d) the pelvic reconstruction system.

abductors were simulated for practical purposes as they provided the main balancing force for the moment around the centre of rotation of the hip. The potting cylinder was fixed to a horizontal platform which was on rollers, allowing anteroposterior and mediolateral translations in the transverse plane, so that only vertical loads were applied to the sacrum.

The load was applied to the end-plate of S1 through a custom-made ball and socket joint on an Instron 5565 materials testing machine (Instron Co., High Wycombe, United Kingdom), and the applied load and vertical displacement were recorded as a hysteresis loop. Vertical compressive loads were applied cyclically by the Instron between $0 \mathrm{~N}$ and a fixed peak load of $50 \mathrm{~N}$, at $120 \mathrm{~mm} / \mathrm{min}$ displacement speed, for up to 2000 load cycles. If the maximum permanent displacement, namely the difference between the displacement at zero load after a number of load cycles, minus the initial displacement was $<2 \mathrm{~mm}$ or 2 degrees in any of the six degrees of freedom, then the load was raised to $100 \mathrm{~N}$ and the cyclic loading repeated. The final incremental loading regimes for the different fixation methods are listed in Table I. The maximum displacement in all six degrees of freedom were recorded.

The fractures were repaired using four methods. For the iliosacral group, an iliosacral screw was inserted in a lateral medial direction at S1 on each side. The screws, $110 \mathrm{~mm}$ in length and $8 \mathrm{~mm}$ in diameter, were partially threaded cancellous screws with a washer (Ace; DePuy, Warsaw, Indiana; Fig. 2a). The tension band plate was a ten-hole $4.5 \mathrm{~mm}$ pelvic reconstruction plate, $3.2 \mathrm{~mm}$ thick, $12 \mathrm{~mm}$ wide and $156 \mathrm{~mm}$ long. In order to secure the plate, six screws were used: an $80 \mathrm{~mm}$ long iliac intertable screw and other screws ranging from $40 \mathrm{~mm}$ to $45 \mathrm{~mm}$ in length (Synthes, West Chester, Pennsylvania; 


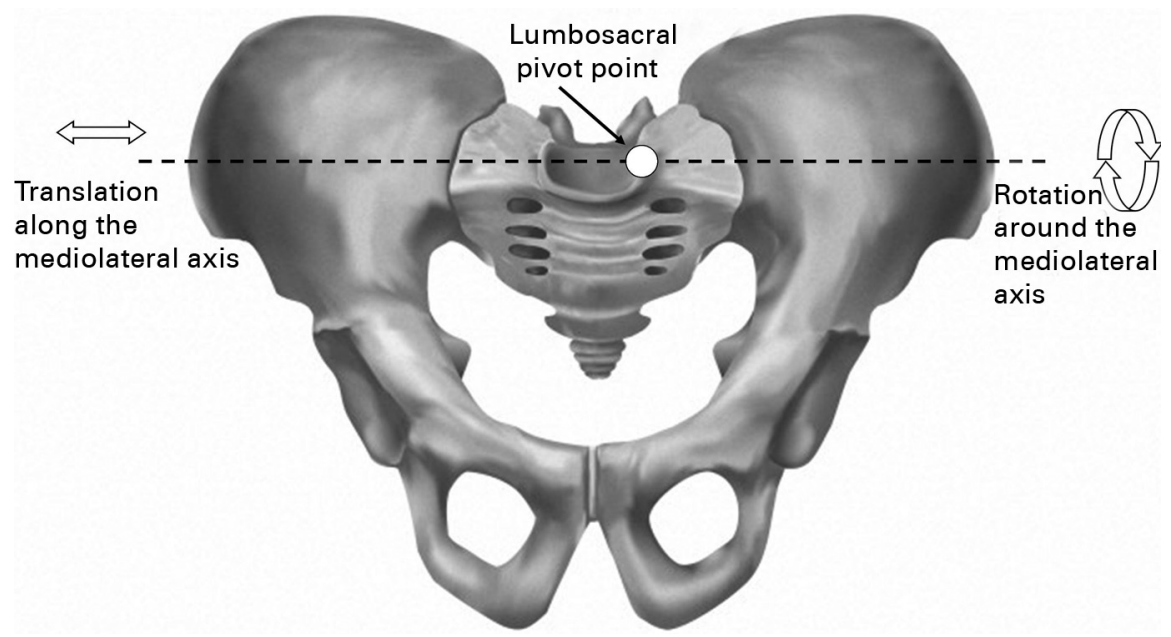

Fig. 3a

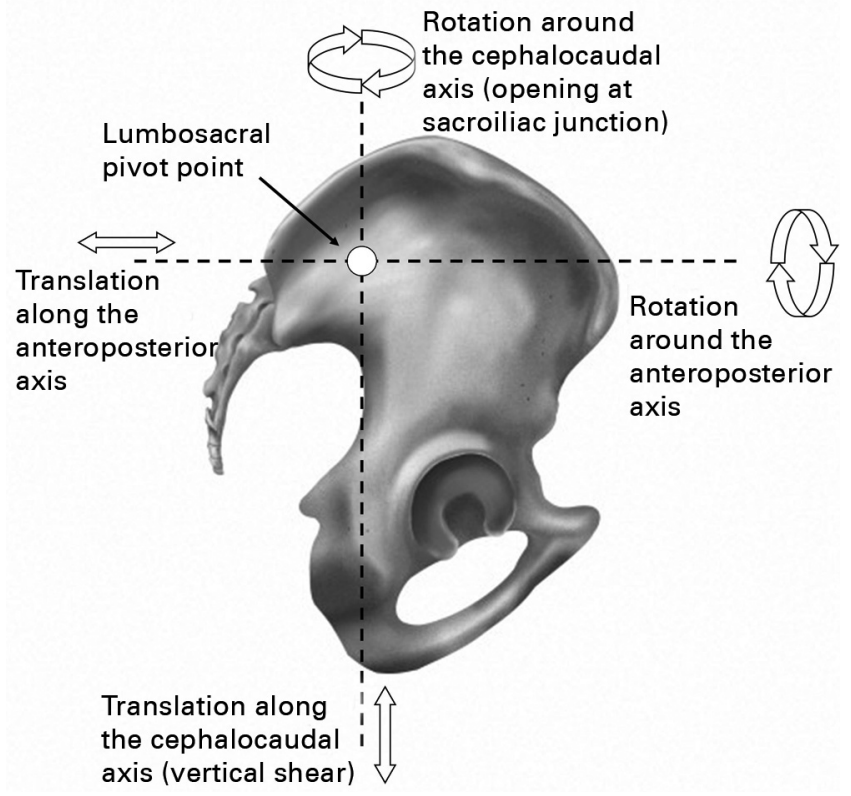

Fig. 3b

Diagrams showing the six degrees of movement and displacement in a) the anteroposterior plane and b) the cephalocaudal and mediolateral planes. A key reference point for the measurements is the lumbosacral pivot point (images modified from the Wellcome Images Library).

Fig. 2b). In the third group the iliosacral screw and tension band plate were used together (Fig. 2c). The pelvic reconstruction system consisted of a trans-sacral coaxial cannulated rod, $150 \mathrm{~mm}$ long and $9 \mathrm{~mm}$ in diameter, and a transiliac cannulated rod, $120 \mathrm{~mm}$ long and $9 \mathrm{~mm}$ in diameter. These were connected to the outer table by $5.5 \mathrm{~mm}$ spinal instrumentation rods and modified spinal instrumentation links composed of a grub and an outer expansion limiting screw. The system also had polyaxial $5.5 \mathrm{~mm}$ standard cancellous pedicle screws inserted into the $\mathrm{L} 5$ pedicles. The pedicle screws were connected to the transiliac rod via a $5.5 \mathrm{~mm}$ rod and hook links (Fig. 2d).
An array of six linear voltage-displacement transducers (LVDT) (DFG/5; Solartron Metrology, Bognor Regis, United Kingdom) was mounted across the fracture site and used to record three-dimensional translational and rotational displacement of the sacrum in relation to the ilium. In order to achieve this, the LVDT sensor frame was attached to the $\mathrm{S} 1$ end-plate and the spherical displacement array was attached to the ilium at the level of the posterior superior iliac spine. The LVDT array system had an accuracy better than $0.1 \mathrm{~mm} /{ }^{\circ}$. The LVDT output was calibrated and analysed in the linear segment of the voltage versus displacement curve. An analogue data stream from 


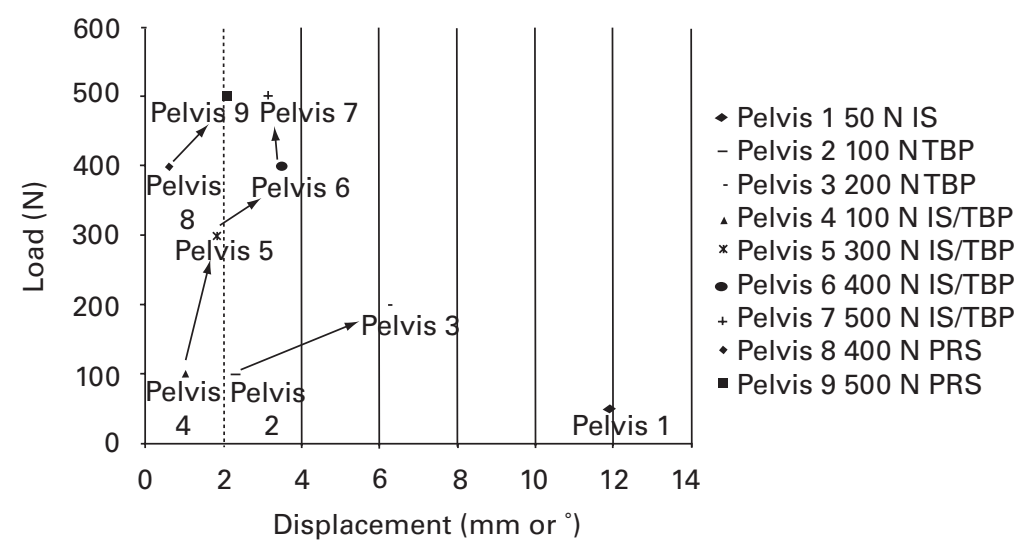

Fig. 4

Graphic depiction showing the maximal displacement that occurred with application of load to the various pelvic constructs. Failure was taken to be $2 \mathrm{~mm}$ translation or $2^{\circ}$ rotation in any direction (dashed line). Arrows indicate increasing $\mathrm{N}$ load tests on pelves with identical fixation (IS, iliosacral screws; TBP, tension band plate; PRS, pelvic reconstruction system).

Table II. The maximal displacements of the sacrum in relation to the ilium on loading the pelvic constructs, the direction of displacement, and the respective outcomes of the load cycle

\begin{tabular}{llll}
\hline $\begin{array}{l}\text { Pelvis construct and load } \\
(\mathbf{N})^{*}\end{array}$ & $\begin{array}{l}\text { Maximum displacement } \\
\left(\mathbf{m m} \text { or }^{\circ}\right)^{\dagger}\end{array}$ & Direction of displacement & Outcome \\
\hline 50 N IS & 11.9 & Translation along craniocaudal axis & Fail \\
100 N TBP & 2.3 & Rotation around mediolateral axis & Fail \\
200 N TBP & 6.2 & Translation along craniocaudal axis & Fail \\
100 N TBP/IS & 1.0 & Rotation around mediolateral axis & Stable \\
300 N TBP/IS & 1.8 & Translation along craniocaudal axis & Stable \\
400 N TBP/IS & 3.5 & Rotation around mediolateral axis & Fail \\
500 N TBP/IS & 3.1 & Rotation around mediolateral axis & Fail \\
400 N PRS & 1.7 & Rotation around mediolateral axis & Stable \\
500 N PRS & 2.1 & Rotation around mediolateral axis & Fail \\
\hline
\end{tabular}

* IS, iliosacral screw; TBP, tension band plate; PRS, pelvic reconstruction system

† linear displacement measured in millimetres; rotational displacement measured in degrees

the LVDT array was amplified and smoothed using a DAQPad 6020E data acquisition device (National Instruments, Austin, Texas). Digital output data were then streamed to a personal computer, where the six channels were analysed with bespoke software written in LabVIEW 7.1 (National Instruments) and the computed dataset was presented in the form of analogue displacement curves corresponding to displacement along or rotation around defined axes. The displacement of the sacrum relative to the ilium was measured in the following six degrees of freedom that transect the lumbosacral pivot point (Fig. 3):

1. Rotation around the anteroposterior axis;

2. Translation along the anteroposterior axis;

3. Rotation around the mediolateral axis in the plane of the sacroiliac joint;

4. Translation along the mediolateral axis;

5. Rotation around the craniocaudal axis, opening at the sacroiliac joint;

6. Translation along the craniocaudal axis: vertical shear.
The data were then analysed for maximal displacement in each of the six degrees of freedom. The complexity of each test specimen meant that it was not practical to perform tests on a larger number of pelves, and therefore no sample size or statistical analysis was undertaken.

Displacement of $2 \mathrm{~mm}$ or two degrees in any one of the degrees of freedom was judged to be clinically relevant and is consistent with other current published data. ${ }^{9}$

\section{Results}

The maximal displacement after loading is shown in Figure 4 and Table II. Displacement is defined as movement of the sacrum with respect to the left hemipelvis along and around the defined axes. These comprised a complex combination of displacements in several planes, which were verified from video data and are summarised in Figure 5.

Iliosacral screws alone were insufficient to withstand even small loads applied to this model (Table III). A load of $50 \mathrm{~N}$ resulted in failure soon after loading, with a maximal 
Table III. The maximal displacements of the sacrum against the ilium after applied load to pelves stabilised with the different methods of fixation

\begin{tabular}{|c|c|c|c|c|c|c|c|c|c|}
\hline \multirow[b]{3}{*}{ Direction of displacement } & \multicolumn{9}{|c|}{ Pelvic construct, ${ }^{*}$ load and displacement $\left(\mathrm{mm} \text { or }{ }^{\circ}\right)^{\dagger}$} \\
\hline & IS & TBP & TBP & IS/TBP & IS/TBP & IS/TBP & IS/TBP & PRS & PRS \\
\hline & $50 \mathrm{~N}$ & $100 \mathrm{~N}$ & $200 \mathrm{~N}$ & $100 \mathrm{~N}$ & $300 \mathrm{~N}$ & $400 \mathrm{~N}$ & $500 \mathrm{~N}$ & $400 \mathrm{~N}$ & $500 \mathrm{~N}$ \\
\hline Rotation around anteroposterior axis & 3.5 & 0.3 & 0.4 & 0.3 & 1.4 & 0.7 & 0.9 & 0.6 & 0.7 \\
\hline Translation along mediolateral axis & 0.6 & 0.8 & 0.7 & 0.1 & 0.9 & 1.7 & 1.6 & 0.4 & 0.4 \\
\hline Translation along anteroposterior axis & 0.3 & 0.2 & 6.0 & 0.1 & 0.4 & 0.2 & 0.5 & 0.5 & 0.6 \\
\hline $\begin{array}{l}\text { Rotation around craniocaudal axis } \\
\text { (opening at } \mathrm{SIJ}^{\ddagger} \text { ) }\end{array}$ & 0.3 & 0.3 & 0.4 & 0.3 & 0.3 & 1.7 & 1.6 & 0.3 & 0.4 \\
\hline Caudal translation (vertical shear) & 11.9 & 0.3 & 6.2 & 0.4 & 1.8 & 0.2 & 2.5 & 0.5 & 0.6 \\
\hline Rotation around mediolateral axis & 4.6 & 2.3 & 2.9 & 1.0 & 0.9 & 3.5 & 3.1 & 1.7 & 2.1 \\
\hline
\end{tabular}

* IS, iliosacral screw; TBP, tension band plate; PRS, pelvic reconstruction system

$\dagger$ linear displacement measured in millimetres; rotational displacement measured in degrees

‡ SIJ, sacroiliac joint

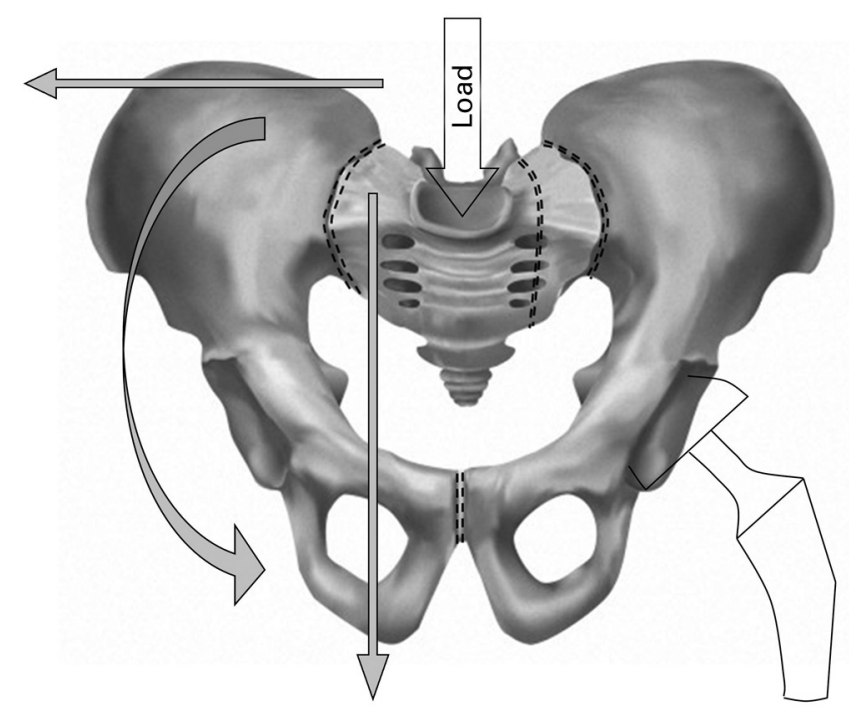

Fig. 5

Diagram showing the direction of displacement of the sacrum and right hemipelvis relative to the left hemipelvis that occurred during loading. Displacements are indicated by arrows and include caudal translation, lateral translation along the mediolateral axis, anterior rotation around the mediolateral axis, and rotation (inversion) around the anteroposterior axis. Dotted lines indicate the fracture configuration (Image modified from Wellcome Images library).

inferior translation of $12 \mathrm{~mm}$, which occurred along the craniocaudal axis. Furthermore, there was considerable rotation around the anteroposterior axis $\left(3.5^{\circ}\right)$ and the mediolateral axis $\left(4.6^{\circ}\right)$. The iliosacral screw failed by loosening at the interface with the left hemipelvis.

A tension band plate was able to withstand a greater load, but failure still occurred at $100 \mathrm{~N}$, with rotational displacement of $2.3^{\circ}$ around the mediolateral axis (Table III). A higher load of $200 \mathrm{~N}$ led to a craniocaudal translation of $6.2 \mathrm{~mm}$, vertical shear, and $6.0 \mathrm{~mm}$ of anteroposterior translation. The tension band plate was, however, very good at resisting rotational displacements around the anteroposterior $\left(0.4^{\circ}\right)$ and craniocaudal axes $\left(0.4^{\circ}\right)$.
The combination of iliosacral screw and tension band plate led to improved stability at an improved stability at the $100 \mathrm{~N}$ load level (Table III). Once again, rotational failure occurred around the mediolateral axis. The application of $400 \mathrm{~N}$ to this construct led to failure of the pelvis at 200 cycles, and when a $500 \mathrm{~N}$ load was applied failure occurred at 100 cycles.

The pelvis reconstruction system was the most stable construct. The application of $400 \mathrm{~N}$ and $500 \mathrm{~N}$ loads led to only minimal displacement in all parameters measured (Table III). The failure threshold of $2^{\circ}$ was just exceeded with rotation of $2.1^{\circ}$ around the mediolateral axis at a load of $500 \mathrm{~N}$, but this remained within the elastic deformation curve and no further displacement was observed at 2000 cycles, at which point the test was discontinued. This was more stable than a pelvis stabilised with an iliosacral screw and tension band plate.

\section{Discussion}

This study has demonstrated that an experimental system for pelvic reconstruction comprising linked transverse parallel rods could resist vertical cyclical loading of simulated unstable fracture configurations better than alternative methods in current clinical use. Compared with iliosacral screws, tension band plates and a combination of the two, the pelvic reconstruction system was the most stable construct, suggesting an advantage for clinical use in maintaining accurate reduction of the fracture and facilitating early weight-bearing.

Vertically and rotationally unstable pelvic fractures may be treated by external fixation, internal fixation or a combination of the two. External fixation alone is insufficient to restore stability to the disrupted pelvic ring. ${ }^{4,11,12}$ External frames do have a role in the resuscitation of a haemodynamically unstable patient, but the fixation should probably be regarded as a temporary measure. ${ }^{1,13}$ Biomechanical testing has shown that for unstable vertical shear injuries, a combination of internal and external fixation is more stable that external fixation alone. ${ }^{12}$ However, superior stability was achieved with plating of the pubic symphysis combined with 
posterior fixation. ${ }^{12,14,15}$ The options available for posterior fixation include one or two iliosacral screws, ${ }^{6,15-19}$ transiliac bars, ${ }^{14,20,21}$ a tension band plate, ${ }^{14,22,23}$ anterior sacroiliac plates ${ }^{5,20,24}$ and triangular osteosynthesis., ${ }^{9,10}$ The developmental pelvic reconstruction system embodies some of the strengths of the techniques currently available and extends them further to create a stable construct for use in managing pelvic fractures, including sacral fractures.

In this study the pelvic reconstruction system was compared with current methods such as iliosacral screws and tension band plates. A very unstable vertical shear-type pelvic fracture configuration consisting of bilateral sacroiliac joint fractures with an ipsilateral sacral transforaminal fracture (Denis type 2) was deliberately chosen. This fracture pattern is unlikely to be encountered clinically, but was chosen to create a state of significant instability for test purposes. A nominal failure displacement of $2 \mathrm{~mm}$ or $2^{\circ}$ was judged to be clinically relevant. Synthetic pelves were used to provide consistent material properties, thereby minimising variability between experiments, and are appropriate for studies of micromovement. Cyclical loading was designed to simulate a single-leg stance. We are not aware of any other published studies that have investigated such an unstable fracture configuration.

The concept of the pelvic reconstruction system incorporates the key biomechanical advantages of iliosacral screw fixation, tension band plate or transiliac bar fixation and triangular osteosynthesis. It also allows load-sharing across the construct and provides for fixation anterior to the lumbosacral pivot point, the importance of which has been pointed out by McCord et al. ${ }^{8}$ This concept was corroborated by Kuklo et a ${ }^{25}$ and Lebwohl et al, ${ }^{26}$ who demonstrated a significant increase in the stability of spinal pelvic instrumentation with the addition of iliac inter-table screws which extended anterior to the pivot point, giving an increase in the load to failure in both axial and flexion-extension loading.

This study demonstrated that the pelvic reconstruction system could resist cyclical deforming loads on the pelvis more effectively than conventional devices. This system remained stable with up to $500 \mathrm{~N}$ of cyclical load, representing approximately body weight minus the weight of the fixed lower limb (Fig. 4). A maximal rotational displacement of $2.1^{\circ}$ occurred around the mediolateral axis (Table III), which reached our chosen failure threshold of $2^{\circ}$, but this remained within the elastic deformation curve and no further displacement was observed at 2000 cycles. The system remained stable in all the other degrees of freedom. Compared with the tension band plate and iliosacral screws, the pelvic reconstruction system resisted load better. The tension band plate and iliosacral screw combination could resist loads of only $100 \mathrm{~N}$ (Tables II and III). Greater loading of this combination led to rotational failure, primarily around the mediolateral axis.

Percutaneous iliosacral fixation offers a reasonable solution for rotationally unstable Tile type-B fractures, but does not facilitate early weight-bearing following Tile type-C fracture-dislocations. Our study has demonstrated that this type of construct failed early under low cyclical loads, with a $12 \mathrm{~mm}$ displacement of the fracture at only $50 \mathrm{~N}$ maximum load. Furthermore, it is not well suited to the fixation of transforaminal fractures because there is a risk of compression of a sacral nerve $\operatorname{root}^{27,28}$ and there is minimal bone stock medial to the fracture line, which places a large lever arm on the fixation. This is corroborated by a study examining the rates of failure of percutaneous iliosacral screws in the treatment of vertically unstable pelvic fractures, when a vertical sacral fracture was significantly associated with failure, ${ }^{18}$ as was observed in this study.

Transiliac rods for the fixation of fractures of the posterior pelvic ring have been reported to offer high stiffness and stability ${ }^{14,20}$ which is likely to be similar to posterior plating of the sacrum. Posterior fixation using a $4.5 \mathrm{~mm}$ transiliac reconstruction plate was demonstrated by Albert et $\mathrm{al}^{22}$ to be of similar strength to transiliac rods. The principal indication for posterior plating is for posterior pelvic fractures with associated transforaminal sacral fractures. ${ }^{29}$ One study assessing unstable vertical shear fractures found that the combination of iliosacral screws and transiliac bars provided the most stable fixation method. ${ }^{20} \mathrm{~A}$ further study found that anterior sacroiliac plates in combination with an iliosacral screw gave a stable construct. ${ }^{14}$ The combination of a tension band plate and an iliosacral screw relative to this was found to be less stiff. ${ }^{14}$ Furthermore, on loading, the combined construct did not prevent rotation around the mediolateral axis, as was seen in this study. In contrast, transiliac rod fixation has a high level of stability under conditions of torsional loading. ${ }^{20} \mathrm{~A}$ combination of a transiliac rod and an iliosacral screw was superior to both sacroiliac plates and iliosacral screws in unstable vertical shear fractures. ${ }^{20}$

This combination has some similarities to the pelvic reconstruction system, although the latter extends the principles further with both a transiliac and a trans-sacral rod, providing rotational stability in all degrees of freedom. Another technique more recently developed for posterior pelvic fixation, especially for unstable transforaminal sacral fractures, is triangular osteosynthesis. ${ }^{9,10}$ This involves the placement of pedicle screws in the lower lumbar vertebrae and into the posterior ilium in conjunction with iliosacral screws to complete the triangular composition of the fixation. This technique has been compared to standard iliosacral screw osteosynthesis and has demonstrated superior stability. ${ }^{9}$ A single case of iatrogenic nerve injury was found with this technique in a series of 19 patients. ${ }^{10}$ The concept of the pelvic reconstruction system extends some of the principles of triangular osteosynthesis, primarily by linking the posterior sacral bar to S1 pedicle screws with $5.5 \mathrm{~mm}$ rods similar to those used in spinal instrumentation, demonstrating increasing stability by preventing rotation around the mediolateral axis.

Based on the biomechanical advantages demonstrated in this study, the pelvic reconstruction system concept has been developed further to provide for a more practical, less invasive and reproducible surgical solution which forms the basis of a subsequent study prior to clinical trial. 
We thank Mr A. Ansari, Specialist Registrar, for his assistance, and Mr D. Mizon and Mr D. Turner from the Department of Biomedical Physics, St George's Hospital, for their assistance with the experimental set-up. The Instron machine was provided by Arthritis Research UK.

No benefits in any form have been received or will be received from a commercial party related directly or indirectly to the subject of this article.

\section{References}

1. Tile M. Pelvic ring fractures: should they be fixed? J Bone Joint Surg [Br] 1988;70-B:1-12

2. Denis F, Davis S, Comfort T. Sacral fractures: an important problem: retrospective analysis of 236 cases. Clin Orthop 1988;227:67-81.

3. Kellam JF, McMurtry RY, Paley D, Tile M. The unstable pelvic fracture: operative treatment. Orthop Clin North Am 1987;18:25-41.

4. Matta JM, Saucedo T. Internal fixation of pelvic ring fractures. Clin Orthop 1989;242:83-97.

5. Leighton RK, Waddell JP, Bray TJ, et al. Biomechanical testing of new and old fixation devices for vertical shear fractures of the pelvis. J Orthop Trauma 1991;5:313-17.

6. Keating JF, Werier J, Blachut $\mathbf{P}$, et al. Early fixation of the vertically unstable pelvis: the role of iliosacral screw fixation of the posterior lesion. J Orthop Trauma 1999;13:107-13.

7. Papakostidis C, Kanakaris NK, Kontakis G, Giannoudis PV. Pelvic ring disruptions: treatment modalities and analysis of outcomes. Int Orthop 2009;33:329-38.

8. McCord DH, Cunningham BW, Shono Y, Myers JJ, McAfee PC. Biomechanical analysis of lumbosacral fixation. Spine 1992;17(8 Suppl):235-43.

9. Schildhauer TA, Ledoux WR, Chapman JR, et al. Triangular osteosynthesis and iliosacral screw fixation for unstable sacral fractures: a cadaveric and biomechanical evaluation under cyclic loads. J Orthop Trauma 2003;17:22-31.

10. Schildhauer TA, Josten Ch, Muhr G. Triangular osteosynthesis of vertically unstable sacrum fractures: a new concept allowing early weight-bearing. J Orthop Trauma 2006;20(1 Suppl):44-51

11. Wild JJ, Hanson GW, Tullos HS. Unstable fractures of the pelvis treated by external fixation. J Bone Joint Surg [Am] 1982;64-A:1010-20.

12. Tile M, McBroom R. Disruption of the pelvic ring. Orthop Trans 1982;6:493

13. Riemer BL, Butterfield SL, Diamond DL, et al. Acute mortality associated with injuries to the pelvic ring: the role of early patient mobilization and external fixation. J Trauma 1993:35:671-5.

14. Yinger K, Scalise J, Olson SA, Bay BK, Finkemeier CG. Biomechanical comparison of posterior pelvic ring fixation. J Orthop Trauma 2003;17:481-7.
15. Sagi HC, Ordway NR, DiPasquale T. Biomechanical analysis of fixation for vertically unstable sacroiliac dislocations with iliosacral screws and symphyseal plating. J Orthop Trauma 2004;18:138-43.

16. Routt MLC Jr, Meier MC, Kregor PJ, Mayo KA. Percutaneous iliosacral screws with the patient supine technique. Operat Tech Orthop 1993;3:35-45.

17. Routt MLC, Kregor PJ, Simonian PT, Mayo KA. Early results of percutaneous iliosacral screws place with the patient in the supine position. J Orthop Trauma 1995:9:207-14.

18. Griffin DR, Starr AJ, Reinert CM, Jones AL, Whitlock S. Vertically unstable pelvic fractures fixed with percutaneous iliosacral screws: does posterior injury pattern predict fixation failure? J Orthop Trauma 2003;17:399-405

19. van Zwienen CM, van den Bosch EW, Hoek van Dijke GA, Snijders CJ, van Vugt AB. Cyclic loading of sacroiliac screws in Tile C pelvic fractures. J Trauma 2005:58:1029-34.

20. Comstock CO, van der Meulen MC, Goodman SB. Biomechanical comparison of posterior internal fixation techniques for unstable pelvic fractures. J Orthop Trauma 1996;10:517-22

21. Gorczyca JT, Varga E, Woodside T, et al. The strength of iliosacral lag screws and transiliac bars in the fixation of vertically unstable pelvic injuries with sacral fractures. Injury 1996;27:561-4.

22. Albert MJ, Miller ME, MacNaughton M, Hutton WC. Posterior pelvic fixation using a transiliac $4.5-\mathrm{mm}$ reconstruction plate: a clinical and biomechanical study. $J$ Orthop Trauma 1993;7:226-32.

23. Krappinger D, Larndorfer $\mathbf{R}$, Struve $\mathbf{P}$, et al. Minimally invasive transiliac plate osteosynthesis for type $\mathrm{C}$ injuries of the pelvic ring: a clinical and radiological followup. J Orthop Trauma 2007;21:595-602.

24. Simpson LA, Waddell JP, Leighton RK, Kellam JF, Tile M. Anterior approach and stabilization of the disrupted sacroiliac joint. J Trauma 1987;27:1332-9.

25. Kuklo TR, Bridwell KH, Lewis SJ, et al. Minimum 2-year analysis of sacropelvic fixation and L5-S1 fusion using S1 and iliac screws. Spine 2001;26:1976-83.

26. Lebwohl NH, Cunningham BW, Dmitriev A, et al. Biomechanical comparison of lumbosacral fixation techniques in a calf spine model. Spine 2002;27:2312-20.

27. Templeman D, Schmidt A, Freese J, Weisman I. Proximity of iliosacral screws to neurovascular structured after internal fixation. Clin Orthop 1996;329:194-8.

28. Routt ML Jr, Simonian PT, Mills WJ. Iliosacral screw fixation: early complications of the percutaneous technique. J Orthop Trauma 1997;11:584-9.

29. Mears DC, Capito CP, Deleeuw H. Posterior pelvic disruptions managed by the use of the Double Cobra Plate. Instr Course Lect 1988;37:143-50. 